\title{
Commentary: Excitement at the interface of disciplines: The mean cumulative function
}

\author{
Eugene H. Blackstone, $\mathrm{MD},{ }^{\mathrm{a}, \mathrm{b}}$ and Jeevanantham Rajeswaran, $\mathrm{PhD}^{\mathrm{b}}$
}

\footnotetext{
From the Departments of ${ }^{\mathrm{a}}$ Thoracic and Cardiovascular Surgery, Heart and Vascular Institute, and ${ }^{\mathrm{b}}$ Quantitative Health Sciences, Research Institute, Cleveland Clinic, Cleveland, Ohio.

Disclosures: Authors have nothing to disclose with regard to commercial support.

Supported in part by the Drs Sidney and Becca Fleischer Heart and Vascular Education Chair, held by Dr Blackstone.

Received for publication July 23, 2019; accepted for publication July 25, 2019; available ahead of print Aug 22, 2019.

Address for reprints: Eugene H. Blackstone, MD, Department of Thoracic and Cardiovascular Surgery, Cleveland Clinic, 9500 Euclid Ave, Desk JJ-40, Cleveland, OH 44195 (E-mail: blackse@ @cf.org).

J Thorac Cardiovasc Surg 2020;160:687-8

$0022-5223 / \$ 36.00$

Copyright (C) 2019 by The American Association for Thoracic Surgery

https://doi.org/10.1016/j.jtcvs.2019.07.069
}

Excitement is at the interface of disciplines. -Dr John W. Kirklin

Observational studies and randomized trials demonstrate that surgical and catheter-based atrial ablation for atrial fibrillation (AF) is associated with prolonged life. ${ }^{1-3}$ But at what cost? That question is answered by Rankin and colleagues $^{4}$ in their study of 3745 Medicare recipients with AF undergoing coronary artery bypass grafting with ( $\mathrm{n}=626 ; 20 \%$ ) or without concomitant surgical ablation for their AF. They document a 29\% risk-adjusted reduction in risk of mortality after 90 days. An 11\% higher cost of the index hospitalization is offset by fewer and less expensive subsequent rehospitalizations, such that by 2 years, costs are equivalent. The clinical implication is that surgical ablation for AF concomitant with coronary artery bypass grafting is both lifesaving and cost effective.

\section{Study Methodology Concerns}

Statistical reviewers were concerned that because many patients had no rehospitalizations, and therefore no costs, the distribution of costs - with a large spike at $\$ 0$ - made cost comparisons treacherous. ${ }^{5}$ The authors addressed this with the sophisticated methodology presented in the Methods and in Appendix E1 and Tables E1-E5. Clinical reviewers remarked that the resulting text was opaque, and statistical reviewers were concerned that the competing risk of death was not accounted for (which might make the cost-effectiveness argument even stronger because death truncates further rehospitalizations).

\section{An Alternative at the Interface of Disciplines}

These concerns take us back more than 40 years to the first recall of an implanted heart valve. In 1971, surgeons

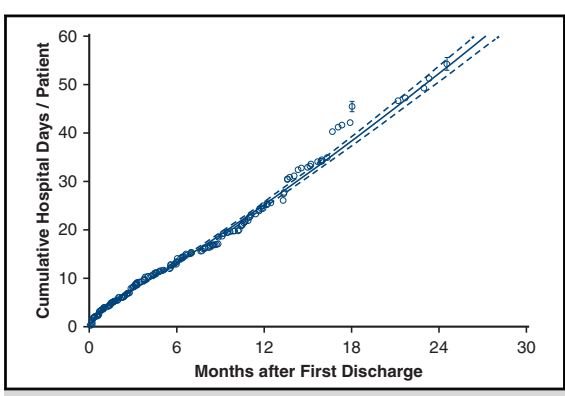

Hospital days accrued per patient after mechanical circulatory support device implantation.

Central Message

Both analysis of repeated events, such as rehospitalizations, and the costs of those events can be graphically depicted and analyzed multivariably using the mean cumulative function.

See Article page 675.

at the University of Alabama Medical Center and Mayo Clinic began implanting a new mechanical aortic ballvalve developed at the National Institutes of Health. ${ }^{6}$ In July 1975 , one of the patients suddenly died when the Silastic poppet escaped from its housing. ${ }^{7}$ During followup, 10 more otherwise well patients were discovered to have experienced poppet escape. Only 2 survived the event.

In attempting to understand the phenomenon and determine whether or not to recall the implanted prostheses, expertise was sought in disciplines outside medicine, among which was industrial reliability. This search introduced us to Dr Wayne Nelson, a statistician and reliability expert at General Electric. Nelson was in Alabama at the time, solving a dilemma for the Alabama Power Company, which had provided households the option of installing kitchen appliances as part of their electric bill. The question was at what point is it cost effective to replace them. Nelson found that the failure rate was constant over time, but that costs of repair escalated across time. He devised a method to handle both repeated appliance repairs and their cost to aid the power company in answering the question. ${ }^{8,9}$

Nelson's time-related method was based on simple counting theory and was not constrained to the probability scale of 0 to 1.0 , as is the venerable Kaplan-Meier product-limit method. It accommodated repeated events, and the event could take on any real value such as the cost of 

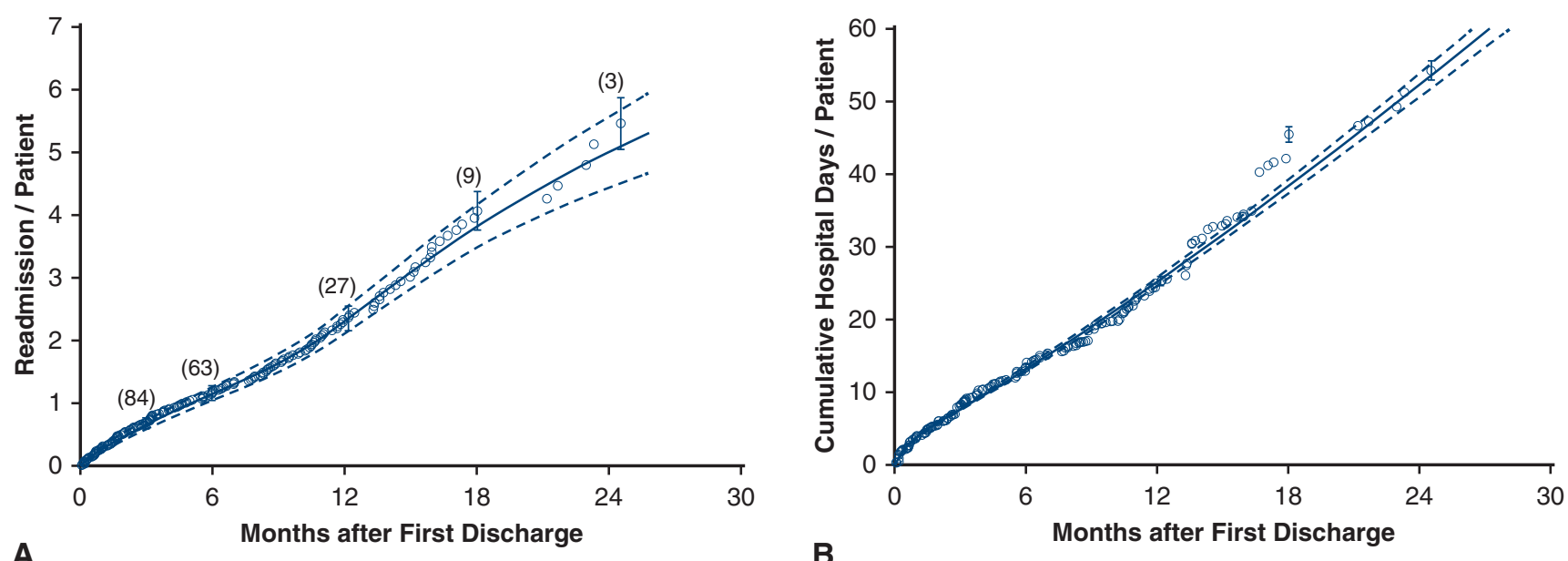

FIGURE 1. Unplanned readmission after implanting a durable mechanical circulatory support device. A, Mean cumulative function depicting repeated readmissions per patient after first discharge following device implantation. B, Cumulative number of days accrued per patient during readmissions after discharge following device implantation. Each readmission is assigned a value of number of days hospitalized. Each symbol is a readmission, vertical bars are asymmetric confidence limits equivalent to \pm 1 standard error ( $68 \%$ confidence interval), and solid line is parametric estimate enclosed within a $68 \%$ confidence band. Numbers are patients at risk (patients continue to be at risk after each readmission).

each repair. Repeat hospitalizations are analogous to repeat repairs, and costs of those hospitalizations are analogous to costs of repairs.

\section{The Mean Cumulative Function}

Nelson's method is known as the mean cumulative function. It is embedded in PROC RELIABILITY and PROC PHREG in SAS (SAS Institute Inc, Cary, NC), in reda $R$ software (R Foundation for Statistical Computing, Vienna, Austria), and in PROC HAZARD, the multiphase nonproportional hazards model developed at the University of Alabama at Birmingham. ${ }^{10}$ In all these software packages, the event, which may be repeating, can be entered as either 0 or 1 or as 0 and a real number.

We find graphical display of mean cumulative function informative for repeated readmissions and costs of these hospitalizations in studies such as those evaluating mechanical circulatory support devices (Figure 1). ${ }^{11}$ It is a readerfriendly visual alternative to the tabular presentation in Table 4 of Rankin and colleagues. ${ }^{4}$ Further, because it is embedded in software related to time-related events, it is a natural vehicle for accounting for the effect on costs of the competing risk of death.

Industrial reliability, meet medical costs!

\section{References}

1. Iribarne A, DiScipio AW, McCullough JN, Quinn R, Leavitt BJ, Westbrook BM, et al. Surgical atrial fibrillation ablation improves long-term survival: a multicenter analysis. Ann Thorac Surg. 2019;107:135-42.

2. Ma Y, Bai F, Qin F, Li Y, Tu T, Sun C, et al. Catheter ablation for treatment of patients with atrial fibrillation and heart failure: a meta-analysis of randomized controlled trials. BMC Cardiovasc Disord. 2018;18:165.

3. Mukherjee RK, Williams SE, Niederer SA, O'Neill MD. Atrial fibrillation ablation in patients with heart failure: one size does not fit all. Arrhythm Electrophysiol Rev. 2018;7:84-90.

4. Rankin JS, Lerner DJ, Braid-Forbes MJ, McCrea ML, Badhwar V. Surgical ablation of atrial fibrillation concomitant to coronary-artery bypass grafting provides cost-effective mortality reduction. J Thorac Cardiovasc Surg. 2020;160:675-86.e13.

5. Liu W, Grunwald GK, Ho PM. Two-part models for cost with zeros to decompose effects of covariates on probability of cost, mean nonzero cost, and mean total cost. Stat Med. 2019;38:2767-82.

6. Schoen FJ, Goodenough SH, Ionescu MI, Braunwald NS. Clinicomorphologic correlations following long-term implantation of cloth-covered prosthetic heart valves: implications for device development. Trans Am Soc Artif Intern Organs. 1983;29:556-62.

7. Blackstone EH, Kirklin JW, Pluth JR, Turner ME, Parr GV. The performance of the Braunwald-Cutter aortic prosthetic valve. Ann Thorac Surg. 1977;23:302-18.

8. Nelson W. Graphical analysis of system repair data. J Qual Technol. 1988;20:24-35.

9. Nelson W. Confidence limits for recurrence data: applied to cost or number of product repairs. Technometrics. 1995;37:147-57.

10. Blackstone EH, Naftel DC, Turner ME Jr. The decomposition of time-varying hazard into phases, each incorporating a separate stream of concomitant information. J Am Stat Assoc. 1986;81:615-24.

11. Smedira NG, Hoercher KJ, Lima B, Mountis MM, Starling RC, Thuita L, et al. Unplanned hospital readmissions after HeartMate II implantation. J Am Coll Cardiol Heart Fail. 2013;1:31-9. 